\title{
Epidemiological study of food poisoning during the period 2001-2018 in the province of Kenitra
}

\author{
Asmaa Elkhal1,2,3, *, Benaissa Attarassi1, Nabila Aujjar1,2, Samira Jayche 1,2,3, Mohamed Lahmam²,3 \\ ${ }^{1}$ Biology and Health Laboratories, Joint Unit "Nutrition, Health and Environment" Ibn Tofail University, Kenitra \\ 2 Department of Biology, Faculty of Sciences, Laboratory of Biology and Health, Unit of Neuroscience and Nutrition, \\ Ibn Tofail University, Kenitra. \\ ${ }^{3}$ Health Delegation of Kenitra.
}

\begin{abstract}
Foodborne illnesses can be the cause of morbidity or mortality. Collective foodborne illnesses (TIAC) are generally benign; their epidemic nature can have a significant impact in terms of public health and socio-economic aspects. The present study intends to establish a database inherent to food poisoning specific to the province of Kenitra during the period 2001-2018. These data will help inform about the current situation and the epidemiological evolution during the summer seasons of the study period. This is a retrospective case study of collective food poisoning. The consulted files include data relating to the number and characteristics of intoxicated persons in the study area, the seriousness of the cases (hospitalization, death), food and germ in question, and the factors that promote such an outbreak. The results show that, between 2001 and 2018, 43 outbreaks of TIAC were notified in the province of Kenitra, involved 367 patients ( 69 hospitalized and 2 deaths). The gender distribution of our sample shows a female predominance ( $\operatorname{sex}$ ratio $\mathrm{M} / \mathrm{F}=0.65)$ with significant difference $(\mathrm{p}<0.01)(60.66 \% \mathrm{~F} ; 39.34 \% \mathrm{M})$, and the age groups varied from 5 to +30 years old of which $71.39 \%$ are under 25 years old.
\end{abstract}

\section{INTRODUCTION}

Collective food poisoning (TIAC) is frequent and sometimes serious. They represent a real public health problem and therefore, are included among the transmissible diseases with mandatory notification. This is a frequent phenomenon in collective catering. In fact, according to the National Institute for Public Health Surveillance (InVS,) in 2009, $68 \%$ of TIACs occurred in collective catering, of which $12 \%$ occurred in schools [1]. TIAC is a public health emergency requiring rapid investigation in order to initiate control measures and make recommendations to prevent recurrence.

According to the WHO report (2015), the estimation of the global burden of disease from foodborne illness ranked first from 31 foodborne agents (bacteria, viruses, parasites, toxins and chemicals).

In Morocco, TIAC represents $11 \%$ of total poisoning. More than $90 \%$ of TIAC are of bacterial origin. A sharp decrease in chemical poisoning and a gradual increase in TIAC over the past ten years have been observed. In fact, the number of cases and episodes of TIAC from 1996 to 2001 has doubled [2].

\subsection{Methods of monitoring}

A focus of collective food poisoning is defined by the occurrence of at least two grouped cases, with a similar symptomatology, generally digestive, the cause of which can be attributed to the same food origin [3] [4]. In cases

\footnotetext{
*Corresponding author: e.asmaa@gmail.com
}

where the epidemic occurs in a school, at work, as well as in restaurants or fast food shops, the managers are required to report urgently the epidemic. They are also expected to collaborate in measures to investigate and control the epidemic. When an outbreak of TIAC occurs, it is an emergency, which allows:

-Urgent care for those affected (clinical aspect),

-Immediate epidemiological investigation of the incident.

-Strengthening prevention measures in collaboration with local authorities and ONSSA (National Office for Food Safety).

The geographical distribution (figure 1) of reported incidents of TIAC shows that all regions of Morocco are concerned by this problem with a significant difference in reporting between regions [5].

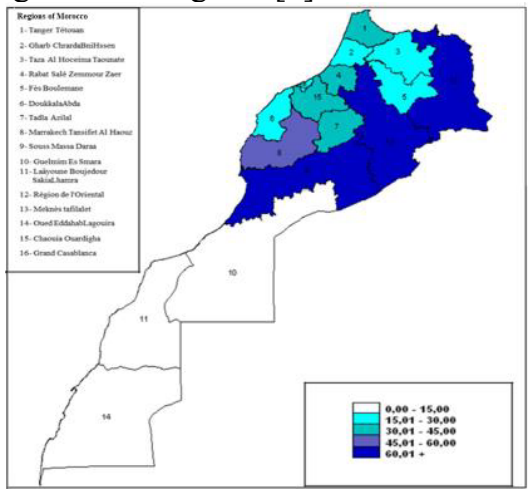

Figure 1: Distribution of the number of TIACs confirmed by region in Morocco (2008-2012) [5]. 


\section{METHODS}

\subsection{Type and period of the study}

This work is a comprehensive retrospective investigation.

\subsection{Studied Population}

This study has targeted persons between 5 and 75 years old, and both gender.

\subsection{Case definition}

In a TIAC, it is important to establish a case definition that includes; a notion of the incubation period, clinical symptoms, and epidemiological link. Based on this, the type of agent suspected and the stage of clinical development of the patients, the number of patients to be sampled to search for the pathogen will be defined. Sampling from patients, meeting the case definition, may however be carried out systematically in the following situations:

-As long as the pathogen is unknown in the context of an active TIAC (appearance of new cases) and prolonged (ascending phase of the epidemic curve):

- In the event of severe symptoms,

- If the cases do not appear to be linked by a common exposure.

-Once the pathogen is identified, the public health management of TIAC no longer requires the collection of patients' samples. In fact, the responding to a probable case definition (clinical signs and epidemiological link) is sufficient. The indication for the sample will then be based on a clinical and therapeutic need.
Anyone presenting clinical signs of the gastrointestinal type are included in this study. The data collection method is based on the study of cases expressed and returned in Kenitra Province. The files consulted include data relating to the number and characteristics of the people affected, the seriousness of the cases (hospitalization, death), the food in question, the germ in cause, and the factors that promote such outbreaks.

\subsection{Data analysis}

The study population was described in terms of age, sex, disease, clinical signs, and evolution. After determining the set of variables, the data was entered into a computerized database. The obtained database was analyzed with Excel and EPI-info7.

\section{RESULTS}

\subsection{Annual change}

Between 2001 and 2018, 43 outbreaks of TIAC were notified in the province of Kénitra, infecting 367 patients (69 hospitalized) and 2 deaths. Analysis of the curve (Figure 2) shows a considerable decrease in cases of TIAC, particularly in 2008 and 2014 with 0 victims. This can be explained either by the absence of TIAC or by under notification. However, the year 2015 was an exception, even if the number of outbreaks does not exceed a single declaration; a very remarkable number of intoxicated people (98 cases) has recorded during this year. This is mainly linked to a collective intoxication of a group of children in a school canteen in Sidi Boubker L'Haj.

\subsection{The inclusion criteria}

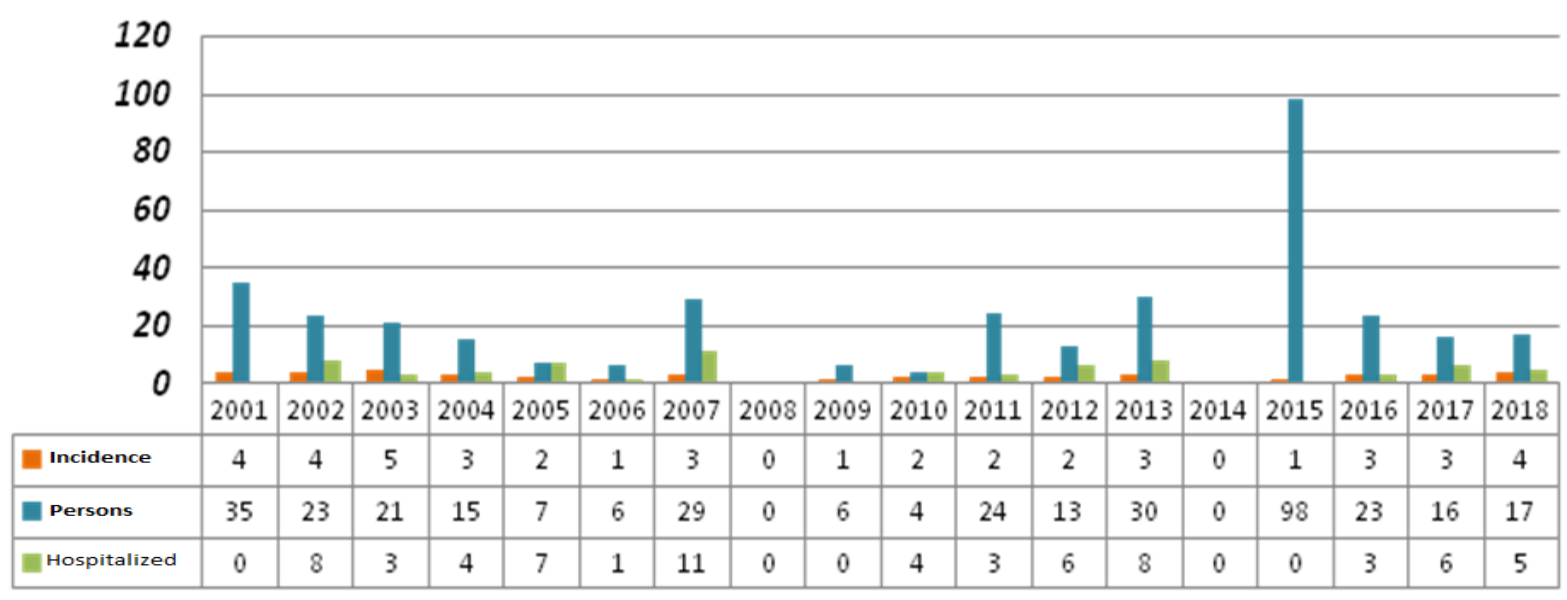

Figure 2 Evolution of reported TIACs according to year of study (2001-2018) in the province of Kenitra

\subsection{Gender Distribution}

The distribution of the sample by sex (Figure 3) shows that $60.66 \%$ of affected people are female and $39.34 \%$ are male with a sex ratio $(\mathrm{M} / \mathrm{F})$ of 0.65 and a significant difference $(\mathrm{p}<0.01)$. 


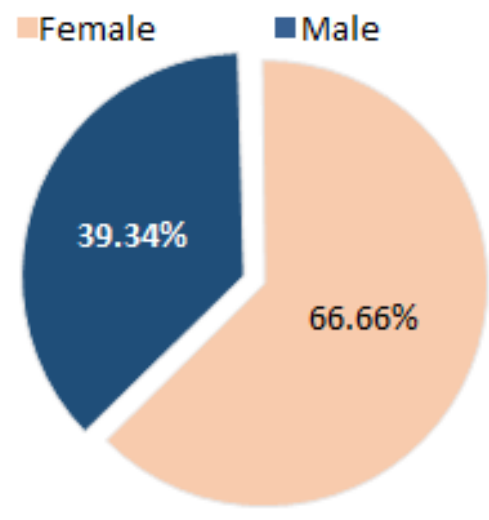

Figure 3: Gender distribution during the study period (2001-2018) in the province of Kenitra

\section{3 distribution according to gender}

According to figure 4 , there is a clear increase in the number of foodborne illness cases in the (5-10) age group, followed by the (10-15), (15-20), and then (2025) age groups, and clear decreases in the other age groups. The most vulnerable age group is the (5-25) years since $71.39 \%$ of the intoxicated are under 25 years. Age groups show the majority involvement of the working population including children, adolescents, and adults. On the other hand, the category of lower risk is those who are over 30 years old.

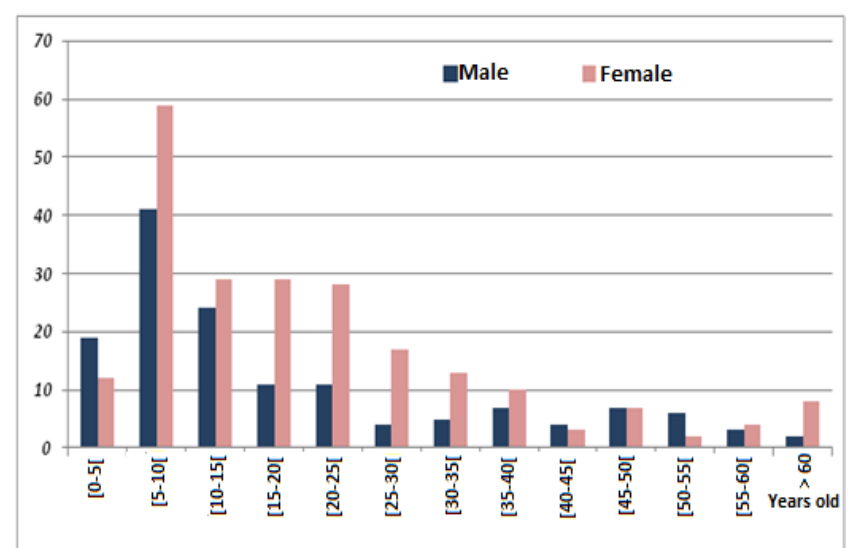

Figure 3: The age distribution of TIACs according to the study period (2001-2018) in the province of Kenitra

\subsection{Distribution by environment}

The percentage of food poisoning cases recorded in rural areas is lower compared to those reported in urban areas. Figure 5 shows that $41.14 \%$ of food poisoning cases occur in rural areas, and $58.86 \%$ in urban areas $(\mathrm{p}<0.01)$.

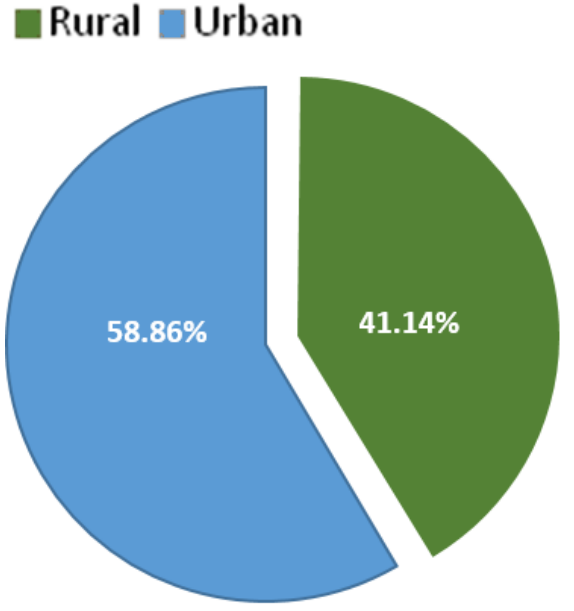

Figure 4: Distribution of TIAC occurrence according to the environment (rural/urban) during the study period (2001-2018) in the province of Kénitra

\subsection{Distribution according to the place of intoxication}

Taking into account the places of onset of intoxication, the results showed that $34.72 \%$ of cases had occurred in family homes, $30 \%$ in canteens, $10 \%$ in street vendors, $6.39 \%$ in pastry shops in restaurants, $5 \%, 3.30 \%$ in grocery stores and $2 \%$ in dairy (Figure 6 and Figure 7 ).

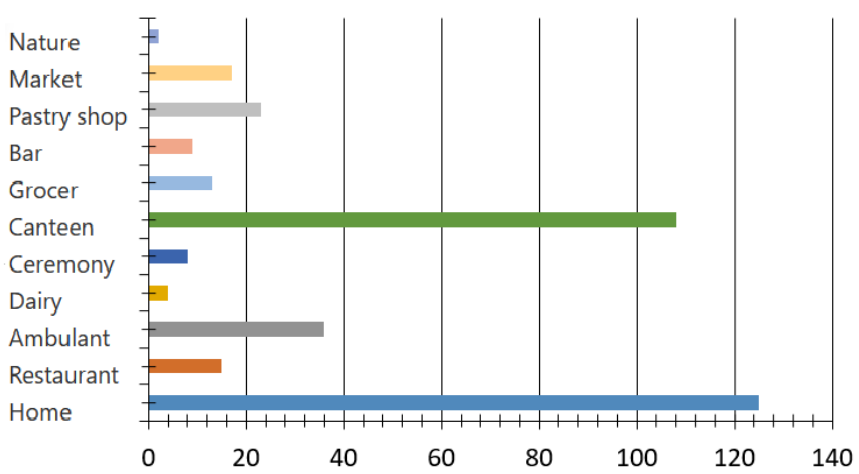

Figure 5: Distribution by place of onset of intoxication in the province of Kenitra (2001-2018)

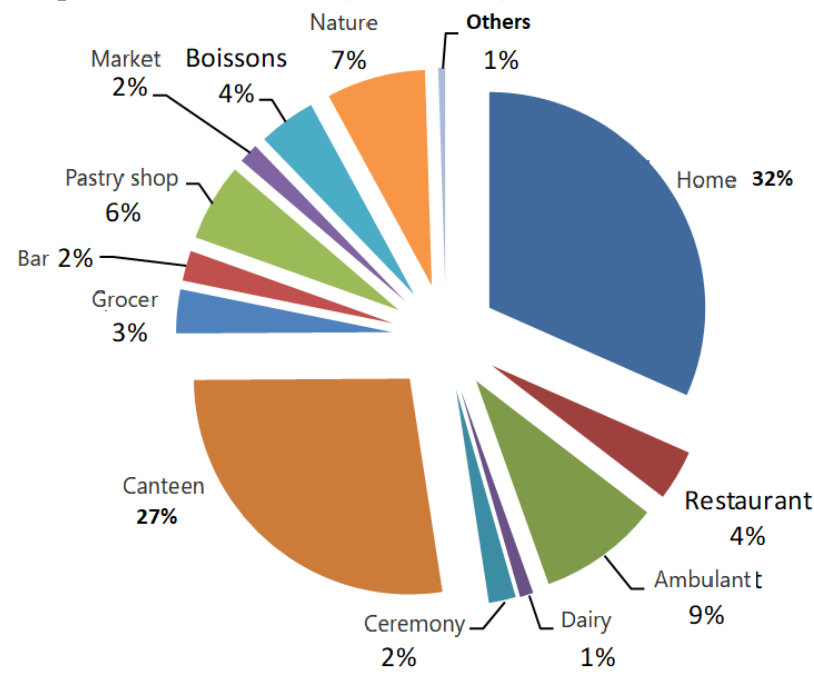

Figure 7: Distribution according to the place of occurrence of intoxication in the province of Kenitra (2001-2018) 


\subsection{Distribution according to clinical symptoms}

The analysis of different clinical symptoms appeared in recorded cases (Figure 8), few minutes after poisoning, has shown two different groups:

\subsubsection{Simple cases}

The subjects seen in consultation presented trivial digestive disorders made up of 321 cases of vomiting,
302 cases of abdominal pain, 132 cases of diarrhea, 127 cases of headache, and 107 had a fever.

\subsubsection{Sever cases}

They represent $18 \%$ of the intoxicated subjects, 36 cases presented with itching, 24 cases with tingling, 14 cases presented with jaundice, 7 with visual disturbances, two cases with delusions, and two cases went into a coma.

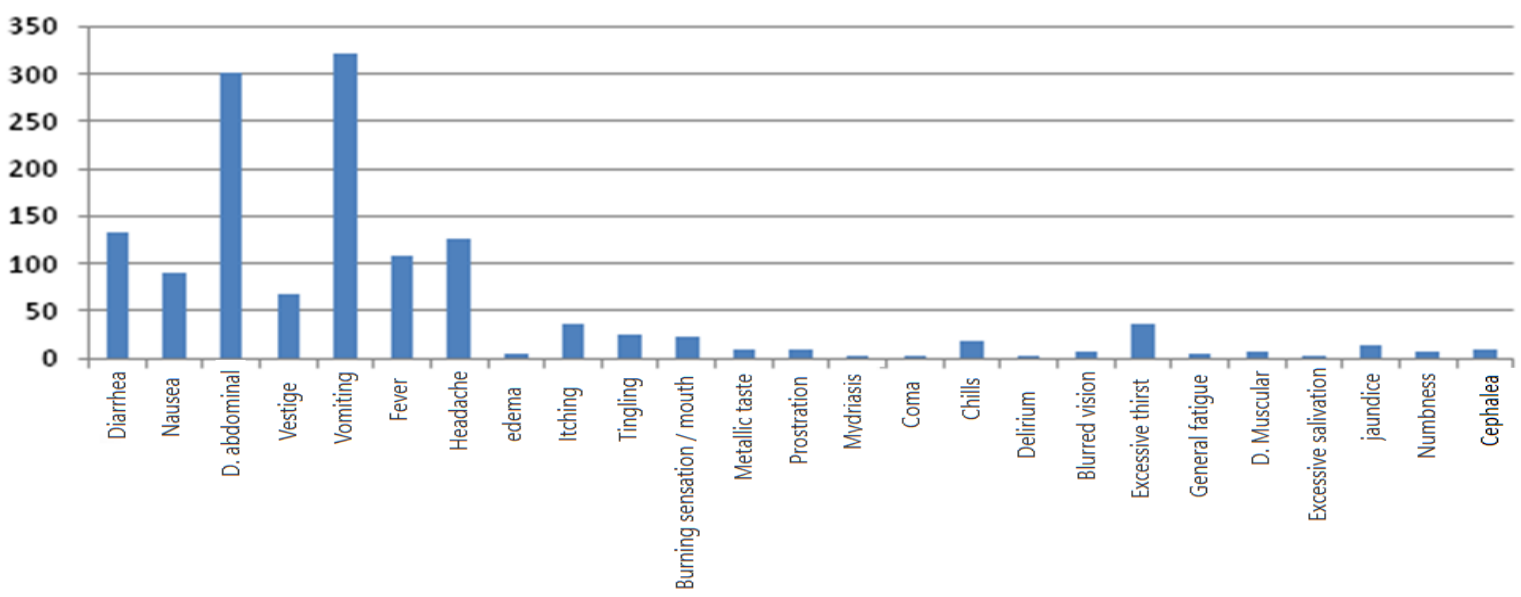

Figure 8: Distribution according to clinical signs in the province of Kenitra (2001-2018)

\subsection{Distribution according to suspect food}

Most of the foodborne outbreaks were due to the consumption of mixed meals (53.85\%). According to our results, fish is the food that causes the most cases, up to 154 cases $(27.85 \%)$, followed by meat and poultry dishes in 79 cases $(14.29 \%), 60$ cases $(10.87 \%)$ consumed milk and its derivatives and $8.14 \%$ (45 cases) ate snails (Table $1)$.

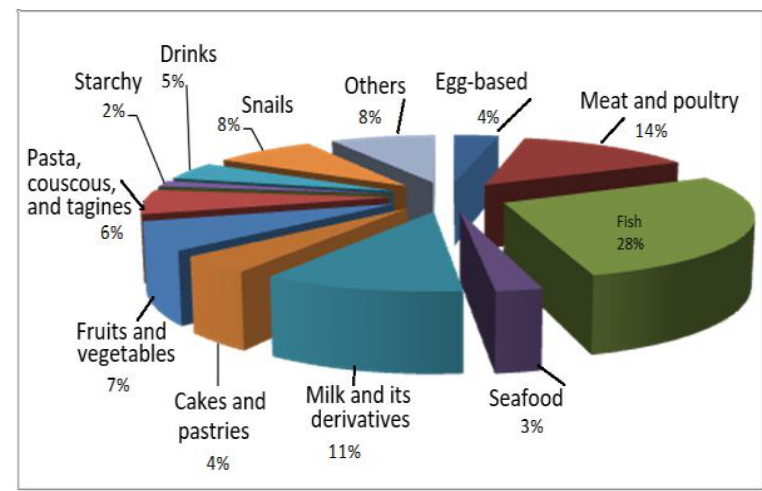

Figure 9: Distribution according to suspected food in the province of Kénitra (2001-2018)

\subsection{Distribution according to causal agent}

The etiological agent responsible for the notified TIACs is confirmed by human samples (stool, blood, and others) in addition to clinical and epidemiological data. In our study, the pathogenic agent involved in the occurrence of foodborne outbreaks was not identified in most of the recorded cases, and remained undetermined in the majority of cases $(90.70 \%)$. While only $9.30 \%$ were determined, probably due to the absence of control dishes at the time of the occurrence of foodborne outbreaks, or by the refusal of patients to undergo testing. In the $9 \%$ of cases where the causal agent is known, $50 \%$ of the intoxications were due to food contaminated by pesticides, $25 \%$ by salmonella, and the two deaths were contaminated by a toxin.

Table 1: Distribution according to suspected food in the

\begin{tabular}{|l|c|}
\hline Suspect Foods & Percentages (\%) \\
\hline Egg-based & 3.62 \\
\hline Meat and poultry & 14.29 \\
\hline Fish & 27.85 \\
\hline Seafood & 2.53 \\
\hline Milk and its derivatives & 10.85 \\
\hline Cakes and pastries & 4.34 \\
\hline Fruits and vegetables & 7.23 \\
\hline Pasta, couscous and tagines & 6.33 \\
\hline Legumes & 0 \\
\hline Starchy & 1.63 \\
\hline Drinks & 4.7 \\
\hline Snails & 8.14 \\
\hline Others & 8.5 \\
\hline
\end{tabular}

province of Kenitra (2001-2018)

\subsection{Distribution according to the evolution}

The evolution of the state of health of the intoxicated persons is generally favorable with a frequency of $99.46 \%$. However, it is important to note that a rate of $0.55 \%$ concerns the two deceased persons.

\section{DISCUSSION}

\subsection{Annual recurrence}

The scatterplot analysis (Figure 10) shows that between 2001 and 2018, the number of outbreaks of TIAC has slightly decreased according to the years $(\mathrm{r}=-0.25$; $\mathrm{p}=0.3$ ), this may be related to health education, and 
citizen awareness, or by the loss of epidemiological information and underreporting of cases.

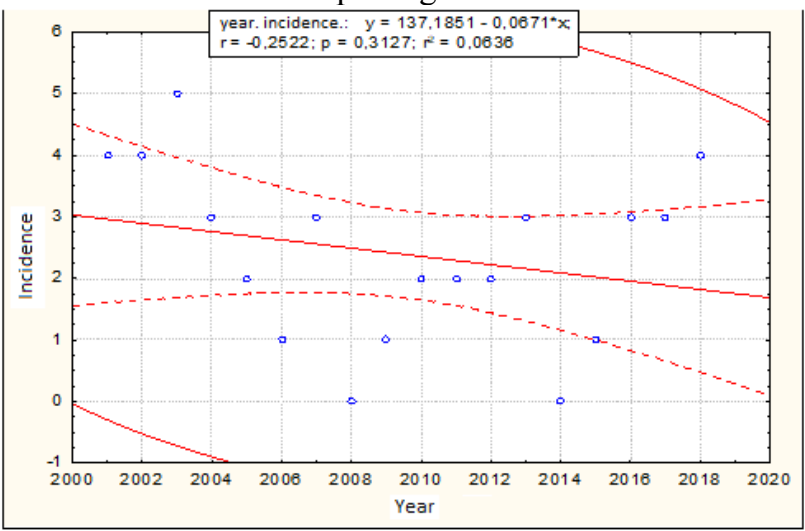

Figure 10 : Annual distribution of TIAC in Morocco

In addition, it is important to note that collective food poisoning (TIAC) is clearly under-reported in Morocco as in other countries of the world [6,7]. Since the Moroccan population is not aware of the risks of TIAC, they are declared only if they worsen. Therefore, we can estimate 10 cases for each statement [8].

\subsection{Distribution according to gender}

Food poisoning affects both sexes randomly because they have the same diet. In our study we noticed that the female is largely the most affected than the male with a significant difference $(\mathrm{p}<0.01)$. Similar results were found by Belomaria (2017) [6] and Karsen (2019) [9] for foodborne botulism, by Nüesch-Inderbinen (2015) for Salmonella enterica [10], and by Patrick (2018) for Campylobacter infection [11]. This is possibly due to the fact that women are more numerous during an incidence of TIAC (98 women poisoned in a canteen). Studies have shown that the female has an increased risk for complications of $E$. coli $\mathrm{O} 157 \mathrm{C}$ infection, although others have not found an association [12] [13]. In addition, the proportion of illness in female patients could be related to gender-specific food preferences [14], but it is not known whether these explanations are adequate. Indeed no one is immune to foodborne illness [15].

\subsection{Distribution according to age}

The TIACs reported in Kenitra Province mainly concern young population including children and adolescents (under 20). It is the age group that ignores hygiene measures outdoors and increase the probability of their food contamination and thus extremely vulnerable to food and water-borne diseases [15]. While adults group (over 20 years) including students and employees, is characterized by its active nature thus undergoing profound and rapid change in lifestyle and eating behavior. In fact, street food is ubiquitous in the city, and sometimes of sub-optimal nutritional and hygienic quality, it is nevertheless convenient and above all inexpensive [16].

4.4 Distribution according to the place of occurrence of the intoxication and the food incriminated
In the majority of TIACs, the mode of contamination remains unclear, several hypotheses are plausible. This is most often the suspicion of a recent meal whose preparation or preservation process has failed.

The risk of foodborne illness is more severe in low- and middle-income countries where it is associated with preparing food with unsafe water, poor hygiene, poor preparation and storage conditions, low levels of literacy and education, and insufficient food safety legislation and enforcement [6].

Our study revealed that the majority of TIACs are associated with family meals followed by those occurring in canteens. This finding is consistent with previous reports that TIACs occurred in the family home [7].

During 2001-2018, the most suspected food products were fish products $(27.85 \%)$, followed by meats and poultry $(14.29 \%)$, then dairy products $(10.85 \%)$ and then snails $(8.14 \%)$ however, the study of Belomaria at the Kenitra level (2017) revealed that the most frequent foods in question were vegetables and fruits, milk and dairy products, fish, poultry and eggs, and snails [6]. Other national studies have shown that dairy products lead the way in food poisoning $[15,17]$. However, no food is spared from causing food poisoning.

According to the obtained results, we were able to distinguish four main places, the family environment with a percentage of $(30 \%)$ followed by canteens $(10 \%)$, in third place is the street vendors $(6.39 \%)$ then the pastry shops $(5 \%)$ the last three areas are very frequented by schoolchildren, students, and workers (in general the young and active population). Our results are similar to those found by Belomaria (2017) [6]. This can be explained by inadequate hygiene practices, both in the handling and maintenance of food in the home. Among which stand out:

-Inadequate refrigeration,

-A longer delay between food preparation and consumption;

-Housewives who suffer from infections and handle food;

-Insufficient warming;

-Maintaining prepared foods in unsuitable places and / or at temperatures favorable for microbial growth;

-Consumption of raw foods at high risk or contain a contaminated ingredient; improper cleaning of kitchen tools;

-Household equipment (refrigerator, stove, microwave, kettle, among others) [18].

\subsection{Breakdown by symptoms and causative agent}

In the event of food poisoning, a clinical sign is not sufficient to confirm the disease, especially when it is as little specific as fatigue, malaise or headache [19]. It is most often a set of symptoms, such as gastrointestinal symptoms (Stomach pain; Diarrhea; Nausea and vomiting; Fever; Headache; Fatigue ...) [20]. Rarer, but more worrying, neurological symptoms may be indicative of botulism or neuromeningeal listeriosis [21]. 
In our study, we observed a predominance of digestive signs (vomiting, abdominal pain and diarrhea) followed by headaches and fevers, results consistent with those found in Morocco in the former Gharb Chrarda Bni Hsen region [22] and in France in the Armies [23].

The causative organism could not be determined in about $91 \%$ of cases and the causative agent could only be identified in $9 \%$ of cases. Similar results were found in other region of Morocco. On the other hand, the agent was identified in $71 \%$ in the ex-region Gharb Chrarda Bni Hsen [22] and in 26.5\% of cases in France [24]. As one of the Notifiable diseases, TIAC is clearly underreported or under-identified [25].

The identification of the causative agent of the notified TIAC is carried out by samples of human origin (stool, blood and others) or from contaminating food in addition to clinical and epidemiological data. Our results show that among the $9 \%$ of the identified causes [26], we found that $50 \%$ of the TIAC are due to food contamination by pesticides followed by salmonella, and toxins that caused the two recorded deaths. According to DELM, 33\% of the results found are due to salmonella, and in a study conducted in Qassim province, Saudi Arabia, the most common causative agent was Salmonella [27]. In the former Gharb Chrarda Bni Hsen region $72 \%$ of cases are Staphylococcus aureus [6]. In the Gharb region, salmonellosis mainly due to contamination of food of animal origin is rare in favor of contamination from water (fruit, vegetables, milk, etc.). The Sebou basin is known for its pollution upstream and its impact on agriculture downstream.

\subsection{Distribution according to changes in the state of health of patients}

During the period of our study and at the level of the province of Kenitra, and according to the severity of the reported cases, $80 \%$ corresponded to outpatients, $18.8 \%$ were hospitalized and $0.54 \%$ had died following the ingestion of toxins. The evolution of the state of health of patients is generally favorable $(99 \%)$, and this is consistent with another study [18]. However, it is important to note that this type of poisoning can be fatal [28].

\section{CONCLUSION}

The present study allows to have a general picture of this morbidity at the provincial level, between 2001 and 2018. In fact, the number of TIAC outbreaks decreased slightly over the last years, this may be related to health education, and public awareness, or by the loss of epidemiological information and underreporting of cases.

Despite the thousands of cases that go unnoticed because not all of them are notified to the health authorities, and although foodborne illnesses can be serious or even fatal, less severe cases often go undetected by routine surveillance. This type of poisoning is more frequent in young age categories including children over 5 years old, adolescents and young people who represent almost $70 \%$ of all recorded cases. Regarding the place of residence of intoxicated people, the majority come from urban areas; this is explained by the spread of collective catering and fast food. In rural areas, the population most often resorts to self-medication. Among the foods incriminated are fish, followed by meat and poultry dishes, then milk and its derivatives. The presence of food contaminants, whether they are poisonings or bacterial or parasitic infections, or a combination of the two (poisoning-intoxication), is very common and mainly affects social groups with few resources.

\section{REFERENCES}

1. Données relative aux TIAC en France (2009).site de l'InVS

2. Abdallah EA, Mohamed R, Latifa $T$. INVESTIGATIONS ANALYTIQUES EN TOXICOLOGIE ALIMENTAIRE: CAS DES INTOXICATIONS ALIMENTAIRES AU MAROC. In: Recueil des résumés de la 2ème Edition des Journées Pratiques Francophones des Sciences Analytiques. (2018).

3. BOURLIOUX P. Les Toxi-Infections Alimentaires. Les habitudes Aliment des 50-60 ans Object Nutr N - 49 Couv LA Lett l'Instutut Danone Les ToxiInfections Aliment Mécanismes prévention. (2000);49.

4. Aliments A canadienne d'inspection des. Causes des empoisonnements alimentaires. (2017).

5. Chiguer B. Toxi-Infections Alimentaires Collectives: Fleau à surveillar (exemple du Maroc 2008-2012). Mohammed V-Souissi; (2014).

6. Belomaria M, Khadmaoui A. Etude du profil épidémiologique des toxi-infections alimentaires collectives dans la région du Gharb Chrarda BniHssen de (2001-2012): étude rétrospective. HAL [Internet]. (2017);01564581.

7. Belliot G, Lopman BA, Ambert-Balay K, Pothier P. The burden of norovirus gastroenteritis: An important foodborne and healthcare-related infection. Clin Microbiol Infect [Internet]. (2014);20(8):724-30.

8. Marnissi B El, Bennani L, Lalami AE oulali, Aabouch M, Belkhou R. Contribution a L ' Etude De La Qualite Microbiologique Et Physicochimique De L' Eau De L' Oued-Zenati ( Guelma ). Rev Microbiol Ind San Environn. (2012);6(1):98-117.

9. Karsen H, Ceylan MR, Bayındır H, Akdeniz H. Foodborne botulism in Turkey, 1983 to 2017. Infect Dis (Auckl) [Internet]. (2019);51(2):91-6.

10. Nüesch-Inderbinen $M$, Cernela $N$, Althaus D, Hächler H, Stephan R. Salmonella enterica Serovar Szentes, a Rare Serotype Causing a 9-Month Outbreak in 2013 and 2014 in Switzerland. Foodborne Pathog Dis. (2015);12(11):887-90.

11. Patrick ME, Henao OL, Robinson T, Geissler AL, Cronquist A, Hanna S, et al. Features of illnesses caused by five species of Campylobacter, Foodborne Diseases Active Surveillance Network (FoodNet) - 2010-2015. Epidemiol Infect. (2018);146(1):1-10. 
12. Gould LH, Demma L, Jones TF, Hurd S, Vugia DJ, Smith K, et al. Hemolytic Uremic Syndrome and Death in Persons with Escherichia coli O157:H7 Infection, Foodborne Diseases Active Surveillance Network Sites, (2000-2006). Clin Infect Dis. (2009);49(10):1480-5.

13. Tserenpuntsag B, Chang HG, Smith PF, Morse DL. Hemolytic uremic syndrome risk and Escherichia coli O157:H7. Emerg Infect Dis. (2005);11(12):1955-7.

14. Coulibaly S, Hami H, Conaré T, Maïga A, Mokhtari A, Soulaymani-Bencheikh R, et al. Les toxiinfections alimentaires dans la commune rurale de Dougabougou, Kati, Mali. Research. (2014); fr1(January 2012).

15. Heiman KE, Mody RK, Johnson SD, Griffin PM, Hannah Gould L. Escherichia coli O157 Outbreaks in the United States, (2003-2012). Emerg Infect Dis. 2015;21(8):1293-301.

16. OMS. Stratégies recommandées par l'OMS contre les maladies transmissibles - prévention et lutte. (2002);201.

17. Allali f. Evolution des pratiques alimentaires au maroc nutrition transition in morocco. Int $\mathrm{J}$ Med Surg. (2017);4(s):68-71.

18. S B, M T, S B, R S, A M, A et S. L' étude des toxiinfections alimentaires au Maroc. In: Conference: Le 1er Congrès National APA, Settat 16 et 17 Mars 2006At: Settat, Maroc.( 2006).

19. Whiley H, Clarke B, Ross K. Knowledge and attitudes towards handling eggs in the home: An unexplored food safety issue. Int $\mathrm{J}$ Environ Res Public Health. (2017) ;14(1).

20. Buisson Y. La toxi-infection alimentaire. Med Mal Infect. (1992);22(SUPPL. 3):272-81.

21. FAYOMI B, JOSSE R, ADAYE A, LALOE V, DJOGBE $\mathrm{H}, \quad \mathrm{ZOHOUN} \quad \mathrm{R}$. Toxi-infection alimentaire en milieu rural béninois. Med Afr Noire. (1992);39(5):364-6.

22. AYB, Teyssou R. LES TOXI-INFECTIONS ALIMENTAIRES COLLECTIVES. Rev Française des Lab. (2002);348:61-6.

23. Belomaria M, Aboussaleh Y, Ahami AOT, Bouazza O, Mahly M. Evolution des toxi-infections alimentaires collectives dans la région du GharbChrarda-Bni Hsein au Nord Ouest du Maroc. (2010);79-84.

24. Mayet A, Manet G, Decam C, Polvèche P, Morisson D, Bédubourg G, et al. Toxi-infections alimentaires collectives dans les armées, (1999-2009): implications épidémiologiques et vétérinaires . Med Armees. (2012);(January).

25. Delmas G, Jourdan N, Pihier N, Vaillant V, Valk H De, Delmas G, et al. Les toxi-infections alimentaires collectives en France entre (2006 et 2008). HAL Id pasteur-02047871. 2010;

26. Agence nationale de sécurité sanitaire de l'alimentation de l'environnement et du travail.
Attribution des sources des maladies infectieuses d' origine alimentaire. (2018).

27. Al-Goblan AS, Jahan S. Surveillance for foodborne illness outbreaks in Qassim, Saudi Arabia, 2006. Foodborne Pathog Dis.(2010);7(12):1559-62.

28. De Valk H, Salvat G. Alimentation et risques infectieux : Enjeux et stratégies pour limiter l'impact sur la santé. Trib la Santé.( 2015);49(4):61-8. 